\title{
The Teaching Exploration of Curriculum Ideology and Politics in Logic General Education
}

\author{
Zhang Wentong \\ School of Tourism Culture, Yunnan University, Lijiang, Yunnan, China \\ 53881168@qq.com

\begin{abstract}
The issuance of the Guidelines for Curriculum Ideology And Politics Construction in Colleges and Universities provides an important policy basis and guidance direction for Curriculum Ideology and Politics in universities. The author combines the relevant content of the Outline and the teaching cases of how to Curriculum Ideology and Politics in the teaching design of Set Concept and Non Set Concept, Conjoint Proposition and Disjunctive Proposition to think about the problems encountered in Curriculum Ideology and Politics.
\end{abstract}

Keywords: Ideological and political courses, Logical General Education, Teaching case

\section{逻辑通识教育中的“课程思政”教学探索}

张文通

云南大学旅游文化学院, 丽江, 云南, 中国

53881168@qq.com

\section{摘要}

《高等学校课程思政建设指导纲要》的发布，为高校的 “课程思政” 提供了重要的政策依据和指导方 向。笔者结合 《纲要》的相关内容和在 “集合概念与非集合概念”、“联言命题”、“选言命题” 的教学 设计中如何 “课程思政”的教学案例来思考在“课程思政”中遇到的问题。

关键词: 课程思政 逻辑通识教育教学案例

\section{1. 前言}

2020 年 5 月 28 日教育部发布《高等学校课程思政 建设指导纲要》(下文简称《纲要》), 在其中指出 “落 实立德树人根本任务, 必须将价值塑造、知识传授和能 力培养三者融为一体、不可割裂。全面推进课程思政建 设, 就是要寓价值观引导于知识传授和能力培养之中, 帮助学生塑造正确的世界观、人生观、价值观, 这是人 才培养的应有之义，更是必备内容。”这为高校 “课程 思政” 教学提供了明确的思路和指导方向。笔者在逻辑 通识教育的教学改革中, 积极探索如何把 “思政” 内容 潜移默化的融入到课程中去。本文将通过三则教学案 例, 来展示笔者在逻辑通识教育的教学中对于 “课堂思 政”教学的思考和探索。

\section{2. 通识教育、逻辑通识教育与 “课程思政”}

通识教育是高等教育中区别于专业教育和职业教 育的组成部分, 是关系着高等教育培养质量的重要部 分, 是一种 “成人教育”。专业教育是为了学生更好的
从事未来的职业而假想他们从事这一范围内的工作所 需要的能力为目的构建的教学活动, 有助于学生专业素 养和学科素养的培养。职业教育是提高学生其职业素养 和技能而构建的教学活动。今天的大学生，不仅是明天 的社会劳动力, 更是未来社会的主体, 职业仅仅是他生 活的一部分。作为人, 他除了工作, 还需要家庭生活和 社会生活。通识教育是一种人文教育, 超越了功利性和 实用性。因此高等教育是完善人性、全面塑造人的完成 阶段。而在这些方面, 正是专业教育所欠缺, 我们需要 通过通识教育培养学生独立思考和独立人格的品质, 把 人的过去、现在、未来连接起来，使学生置身于人的历 史和整体中去成长。

通识教育分为哲学社会科学素养、人文素养、自然 科学与技术素养、美学艺术素养、实践能力素养等五大 模块, 逻辑教育是通识教育的核心组成部分, 它贯穿于 整个通识教育的全过程。在笔者撰写的教学大纲中, 教 学目的是 “通过本课程的学习, 培养学生正确使用概念、 判断和演绎推理进行思考的能力, 同时提高学生发现生 活中逻辑错误的能力, 使其学会用正确的思维方式分析 问题，从而正确解决学习和工作中遇到的问题。”从这 里可以看出逻辑教育就是培养学生有效的思考、清晰的 表达、恰当的辨别善与恶的能力，这与 “课程思政”中 
的相关要求是一致的, 只是没有这么突出强调。因此在 逻辑同时教育的改革中就需要加入 “育人” 元素, 这是 “传道授业解惑” 的师道古训的一种践行, 是一种自然 的过程, 把逻辑通识教育等课程上升为与 “思想政治理 论课” 同向同行的、必不可少的育人手段。因此在逻辑 通识教育的教学中, 高校教师需要在平时的教学基础上 认真进行教学设计, 积极探索教学方法和手段。

\section{3. “课程思政” 教学案例一: 集合概念}

“集合概念和非集合概念” 是逻辑通识教育中学生 遇到的第一个难点。教材中对于这两个概念关键性的描 述主要有 “一定数量同类事物的个体可以构成一个集合 体，即一个不可分割的整体，反映这种由同类个体事物 构成的不可分割的整体的概念就是集合概念”、“第一, 集合体所具有的属性，其构成分子（个体）未必具有， 而分子所具有的属性，其集合体也不必然具有。” “第 二, 有的语词可以在集合意义下使用 (因而具有集合概 念的性质), 也可以在一般的分别的意义下使用 (因而 具有非集合概念的性质)。” 学生在老师讲完这段知识 后, 从文字上没有任何难点, 但是在使用过程中总是没 有办法区别这两者，特别是对集合体的属性难以理解， 笔者就通过举现实生活中的案例加入 “课程思政” 的元 素来引导学生进行认识。

笔者的教学设计就是结合目前我国的反腐工作进 行构建。自十八大以来, 反腐败工作就被提上了重要的 工作日程, 作为一项常抓不解的工作, 一大批 “老虎” “苍蝇” 被绳之以党纪国法, 党风政风为之一新, 极大 地振奋了党心军心民心。习近平随后十九大报告中对反 腐败斗争也作了重要论述, 他严肃指出: “反腐败斗争 形势依然严峻复杂, 巩固压倒性态势、夺取压倒性胜利 的决心必须坚如磐石。” 当然在反腐过程中也遇到了一 些负面问题, 比如大量腐败分子是中国共产党党员的身 份问题。如何引导学生正确认识这个问题呢? 我结合 “集合概念” 来解决。首先我告诉学生们 “中国共产党 是中国工人阶级的先锋队, 同时是中国人民和中华民族 的先锋队, 是中国特色社会主义事业的领导核心, 代表 中国先进生产力的发展要求, 代表中国先进文化的前进 方向, 代表中国最广大人民的根本利益。党的最高理想 和最终目标是实现共产主义。” 这是在《中国共产党党 章》中对于中国共产党的属性的规定, 尽管中国共产党 是由一个个中国共产党员组成的, 但是这一属性并不是 每一个党员必然都具有, 在我党的队伍中肯定存在着有 些腐败分子, 这是由中国共产党的 “集合概念” 的逻辑 性质决定的; 因此尽管在现实生活中有的腐败分子具有 中国共产党员的身份, 他们只是个例, 腐败属性和中国 共产党没有关系。同时这也是我党为什么把从严治党作 为中国共产党治党的重要原则, 在改革开放和社会主义 现代化建设条件下加强党的建设的基本方针和要求的 逻辑基础。因为只有 “从严治党”才能让中国共产党适 应执政、改革开放和发展社会主义市场经济的新情况新 问题, 从严治党, 用习近平新时代中国特色社会主义思
想武装全党，加强党性教育、提高思想觉悟，弘扬优秀 传统文化，增强 “四个自信”，扑下身子深入群众，埋 头苦干真抓实干，真正做到凡是群众反映强烈的问题都 要严肃认真对待, 凡是损害群众利益的行为都要坚决纠 正，以永远在路上的坚韧和执着，真正做到人民群众反 对什么、痛恨什么, 就坚决防范和纠正什么。这是党和 国家的大政方针和政策，也是符合逻辑规律的。教师在 课堂上通过用 “集合概念” 的逻辑规律的梳理, 一方面 让学生学到逻辑思维的方法, 另一方面也联系实际也帮 助学生增强了 “四个意识”、坚定了 “四个自信”、做到 了“两个维护”。在《纲要》中指出要 “推进习近平新 时代中国特色社会主义思想进教材进课堂进头脑。坚持 不解用习近平新时代中国特色社会主义思想铸魂育人, 引导学生了解世情国情党情民情, 增强对党的创新理论 的政治认同、思想认同、情感认同，坚定中国特色社会 主义道路自信、理论自信、制度自信、文化自信。”这 就要求教师在课程的教学设计中, 一方面要引导学生掌 握所学的相关知识, 另一方面要结合结合相关理论引导 学生对我国政治生活中存在的问题进行全面深刻的认 识。

\section{4. “课程思政” 教学案例二: 联言命题}

在复合命题中 “联言命题” 并不是难点, 学生能够 较为容易的掌握相关知识, 但是 “联言命题” 的逻辑含 义却有助于学生的健康的人生观和价值观的培养。理解 这一知识, 可以帮助学生解决在日常生活中的许多现实 问题。

教材中对于 “联言命题” 的关键描述是 “联言命题 是断定事物的若干种情况同时存在的命题”。在这里教 学时笔者会联系习近平总书记的构建人类共同体的理 念来引导学生认识 “若干种情况同时存在” 的描述。习 近平在 2013 年提出 “命运共同体”; 2015 年分别在亚洲 博鳌论坛和第七十届联合国大会中提出 “构建人类共同 体”; 2017 年 1 月, 在联合国日内瓦总部演讲时, 习近 平对如何构建人类共同体又做了进一步解释。因此在国 际上有好多人认为这是中国在强大后争夺世界话语权 的体现, 但是并非如此。如果从逻辑学的角度来说这是 联言思维中 “若干种情况同时存在” 的在现实生活中的 体现。习近平总书记在十九大报告中指出, 当今世界处 于大发展、大变革与大调整的时期, 但和平与发展仍是 时代的主题。虽然全球的治理体系与国际秩序的变革正 加速推进, 世界各国相互联系与依存也日益加深, 但是, 国际力量更趋平衡, 并且和平与发展的大势仍不可逆 转。与此同时, 世界面临的不稳定性与不确定性非常突 出, 全球增长动力不足, 贫富分化严重, 恐怖主义问题、 网络安全问题、传染性疾病问题等威胁蔓延, 当今人类 面临着许多共同的挑战。这是倡导人类命运共同体的全 球现实依据。而如何建设人类共同体呢? 习近平总书记 用五个 “要” 系统阐述了怎样构建人类命运共同体，即 要相互尊重、平等协商, 坚决摒弃冷战思维和强权政治; 要坚持以对话解决争端、以协商化解分歧; 要同舟共济, 
促进贸易和投资自由化便利化；要尊重世界文明多样 性; 要保护好人类赖以生存的地球家园。而在 2020 年 抗击新冠肺炎中，中国从 “一省对一市” 的国内防疫策 略到走出国门的 “一省对一国” 的对外抗疫行动, 再次 证明了和谐共存的 “人类共同体” 的现实意义。国家与 国家虽然制度不同, 社会文化不同, 但是在这样一个“地 球村” 的时代, 可以存在竞争, 但是早已过了你死我忘 得时代, 应该是互惠互利, 相互共存。在这里还可以继 续引导学生认识到, 不仅国家与国家是如此, 我们在现 实生活中处理问题的时候也要注意保持一颗宽容的心, 求同存异，生活中不是你死我亡对立的现实，而是在可 以在竞争中共同进步的。在《纲要》中指出要 “深入挖 掘各类课程和教学方式中蕴含的思想政治教育资源, 让 学生通过学习, 掌握事物发展规律, 通晓天下道理, 丰 富学识, 增长见识, 塑造品格, 努力成为德智体美劳全 面发展的社会主义建设者和接班人。”这就要求教师在 课程的教学设计中, 一方面要引导学生掌握所学的相关 知识, 另一方面还要结合相关理论引导学生对国际问题 进行全面深刻的认识。

\section{5. “课程思政” 教学案例三: 选言命题}

教材中对选言命题的关键描述是 “选言命题是断定 事物若干种可能情况的命题”。我在教学设计中会充分 的利用贴近学生生活案例来引导学生认识其逻辑含义。 比如, 我们的人生是存在着众多选择的机会的, “山重 水复疑无路, 柳岸花明又一村”, 当我们感觉在生活中 某一条路走不通时, 不一定要撞了南墙才回头, 换一种 选择, 换一个思路, 说不定就走出另一片天地。特别是 针对当前的大学生的情感生活来说, 大学生开始谈恋爱 的情况是较多的, 但是他们的情感承受能力是比较脆弱 的, 时常会出现有的同学因为失恋而抑郁甚至寻死受活 的案例, 我就在这里通过一句调㑆性打流行语 “天涯何 处无芳草, 何必独恋一枝花” 来开导学生, 人生的选择 何其多, 何必为了一个歪瓜裂疋放弃自己人生更多选择 的机会; 还有可以针对即将毕业的学生, 我也会告诉他 们, 找工作是一个考验耐心的活, 作为一个刚毕业的求 职者在找工作中碰壁和失败是难免的, 我们应该在失败 后积极总结经验和教训, 为下一个选择做好充分的准 备, 机会总是垂青那些有准备的人, 而这些鸡汤类的许 多人生格言, 背后隐藏的正是宣言命题的基本逻辑特性 “若干种可能情况”。学生在掌握这一逻辑特性出现的 逻辑问题就是只知道有两项选言肢的逻辑问题的解决 方法, 往往忽略有三个以上选言肢时, 如果不能够穷尽 选言肢, 还按照两项选言肢选言命题的逻辑规则进行推 理就会出现问题。在《纲要》中指出要 “培育和践行社 会主义核心价值观。教育引导学生把国家、社会、公民 的价值要求融为一体, 提高个人的爱国、敬业、诚信、 友善修养, 自觉把小我融入大我, 不断追求国家的富强、 民主、文明、和谐和社会的自由、平等、公正、法治, 将社会主义核心价值观内化为精神追求、外化为自觉行 动。” 这就要求教师在课程的教学设计中, 一方面要引
导学生掌握所学的相关知识, 另一方面还要引导学生树 立正确看待人生问题的方法。

\section{6. 逻辑通识教育中 “课程思政” 的反思}

在《纲要》中指出 “要紧紧抓住教师队伍 “主力军”、 课程建设 “主战场”、课堂教学 “主渠道”, 让所有高校、 所有教师、所有课程都承担好育人责任, 守好一段渠、 种好责任田，使各类课程与思政课程同向同行，将显性 教育和隐性教育相统一, 形成协同效应, 构建全员全程 全方位育人大格局。”因此教育部在近期不断发生受过 高等教学的国人辱华事件、高校教师辱华事件的背景 下, 高度重视 “课程思政” 在教学活动中的作用具有十 分重要的现实意义。高校教师应该从自身做起，高度重 视思政教育的建设, 积极学习和思考相关理论知识, 关 注社会热点, 关心学生生活, 坚持教书和育人相统一, 坚持言传和身教相统一，坚持潜心问道和关注社会相统 一, 坚持学术自由和学术规范相统一, 争取做到以德立 身、以德立学、以德施教。其次在教学设计中立足培养 中国特色社会主义事业建设者和接班人的需要，立足国 际视野、家国情怀、集体精神和创新思维的新时代人才 基本需求，自觉做先进思想文化的传播者、党执政的坚 定支持者, 更好担起学生健康成长指导者和引路人的责 任, 争取做一个有理想信念、有道德情操、有扎实学识、 有仁爱之心的 “四有” 好老师。

“课程思政” 是春风化雨, 润物细无声的一种教学 活动。面对已经有独立思维能力的大学生, 高等学校教 师一定要认真思考如何把教学内容和思政教育密切结 合, 避免高高在上的说教, 要按照《规定》中指出的 “深 入挖掘各类课程和教学方式中蕴含的思想政治教育资 源, 让学生通过学习, 掌握事物发展规律, 通晓天下道 理, 丰富学识, 增长见识, 塑造品格, 努力成为德智体 美劳全面发展的社会主义建设者和接班人。”

\section{7. 结论}

总之，“课程思政”是教育部针对我国高等教育教学 中存在的问题提出指导性的解决方案，身为高校教师应该 结合自身的学科特点, 积极思考和探索课程改革, 提高高 等教育的人才培养质量, 我们应该一方面要应该培养什么 人, 另一方面要明确如何培养人。加强教育强国的建设, 我们永远在路上!

\section{项目基金:}

本文为云南省高等学校本科教育教学改 革研究项目（项目编号：JG2018289）阶段性 成果之一。 


\section{REFERENCES}

[1] Ge Y, (2016) Discussion on College General Education and Logic Education, Education Review, 9:29-31

[2] Feng Y, Tang Q, (2017) The profound connotation and value of the thought of the community of human destiny of Xi Jinping, Contemporary World ,11:11-14

[3] Huang Y, Xu L, (2019) Study on quantitative evaluation of classroom teaching quality under "curriculum politics ", Science and Technology Bulletin ,10:217-221 